FACTA UNIVERSITATIS (NIŠ)

Ser. Math. Inform. Vol. 35, No 2 (2020), 283-293

https://doi.org/10.22190/FUMI2002283P

\title{
FIXED POINTS FOR TWO PAIRS OF ABSORBING MAPPINGS IN WEAK PARTIAL METRIC SPACES
}

\author{
Valeriu Popa and Alina-Mihaela Patriciu
}

(C) 2020 by University of Niš, Serbia | Creative Commons Licence: CC BY-NC-ND

\begin{abstract}
In this paper, a general fixed point theorem for two pairs of absorbing mappings in weak partial metric space, using implicit relations, has been proved.

Keywords: weak partial metric space; fixed point; pointwise absorbing mappings; implicit relation.
\end{abstract}

\section{Introduction}

In 1994, Matthews [13] introduced the concept of partial metric space as a part of the study of denotational semantics of dataflow networks and proved the Banach contraction principle in such spaces. The notion of partial metric spaces plays an important role in the constructing models in theory of computation.

Many authors studied the fixed points for mappings satisfying some contractive conditions in [1], [3], [11] and in other papers. In [11], some fixed point theorems for particular pairs of mappings are proved, generalizing some results from [1] and [3].

In 1999, Heckmann [10] introduced the notion of weak partial metric spaces, which is a generalization of partial metric spaces. Some results for mappings in weak partial metric spaces have been recently obtained by[2] and [4].

The notion of absorbing mappings have been introduced and studied in [5] - [7] as well as in other papers. Some fixed point theorems for two pairs of absorbing mappings in metric spaces have been proved in [12], [14], [15].

Several classical fixed point theorems and common fixed point theorems have been unified considering a general condition by an implicit relation in [16] - [18] and in other papers. Recently, the method has been used in the studies of fixed points in metric spaces, symmetric spaces, quasi - metric spaces, $b$ - metric spaces, Hilbert

Received February 11, 2019; accepted October 05, 2019

2010 Mathematics Subject Classification. Primary 54H25; Secondary 47H10 
spaces, ultra - metric spaces, convex metric spaces, compact metric spaces, in two and three metric spaces, for single valued mappings, hybrid pairs of mappings and set-valued mappings.

Some fixed point theorems for pairs of mappings satisfying implicit relations in partial metric spaces have been proved in [8], [9], [19] - [21].

Some results for pointwise absorbing mappings satisfying implicit relations have been obtained in [15].

The purpose of this paper is to prove a general fixed point theorem for two pairs of pointwise absorbing mappings in weak partial metric spaces using an implicit relation.

\section{Preliminaries}

Definition 2.1. ([13]) A partial metric on a nonempty set $X$ is a function $p$ : $X \times X \rightarrow \mathbb{R}_{+}$such that for all $x, y, z \in X$ :

$\left(P_{1}\right): x=y$ if and only if $p(x, x)=p(y, y)=p(x, y)$,

$\left(P_{2}\right): p(x, x) \leq p(x, y)$,

$\left(P_{3}\right): p(x, y)=p(y, x)$,

$\left(P_{4}\right): p(x, z) \leq p(x, y)+p(y, z)-p(y, y)$.

The pair $(X, p)$ is called a partial metric space.

If $p(x, y)=0$, then $x=y$, but the converse does not always hold true.

Each partial metric $p$ on $X$ generates a $T_{0}$ - topology $\tau_{p}$ on $X$ which has as base the family of open $p$ - balls $\left\{B_{p}(x, \varepsilon): x \in X, \varepsilon>0\right\}$, where $B_{p}(x, \varepsilon)=\{y \in X$ : $p(x, y) \leq p(x, x)+\varepsilon\}$ for all $x \in X$ and $\varepsilon>0$.

If $p$ is a partial metric on $X$, then

$$
d_{w}(x, y)=p(x, y)-\min \{p(x, x), p(y, y)\}
$$

is a ordinary metric on $X$.

A sequence $\left\{x_{n}\right\}$ in a partial metric space $(X, p)$ converges with respect to $\tau_{p}$ to a point $x \in X$, denoted $x_{n} \rightarrow x$, if and only if

$$
p(x, x)=\lim _{n \rightarrow \infty} p\left(x_{n}, x\right) .
$$

Remark 2.1. Let $\left\{x_{n}\right\}$ be a sequence in a partial metric $(X, p)$ and $x \in X$. Then $\lim _{n \rightarrow \infty} d_{w}\left(x_{n}, x\right)=0$ if and only if

$$
p(x, x)=\lim _{n \rightarrow \infty} p\left(x_{n}, x\right)=\lim _{n, m \rightarrow \infty} p\left(x_{n}, x_{m}\right) .
$$


Definition 2.2. ([13])

a) A sequence $\left\{x_{n}\right\}$ in a partial metric space $(X, p)$ is called a Cauchy sequence if $\lim _{n, m \rightarrow \infty} p\left(x_{n}, x_{m}\right)$ exists and is finite.

b) A partial metric space $(X, p)$ is said to be complete if every Cauchy sequence $\left\{x_{n}\right\}$ in $X$ converges with respect to $\tau_{p}$ to a point $x \in X$ such that

$$
p(x, x)=\lim _{n, m \rightarrow \infty} p\left(x_{n}, x_{m}\right) .
$$

Definition 2.3. ([10]) A weak partial metric on a nonempty set $X$ is a function $p: X \times X \rightarrow \mathbb{R}_{+}$such that for all $x, y, z \in X:$

$\left(w P_{1}\right): x=y$ if and only if $p(x, x)=p(y, y)=p(x, y)$,

$\left(w P_{2}\right): p(x, y)=p(y, x)$

$\left(w P_{3}\right): p(x, z) \leq p(x, y)+p(y, z)-p(y, y)$.

The pair $(X, p)$ is called a weak partial metric space.

Obviously, every partial metric space is a weak partial metric space, but the converse is not true.

For example, let $X=[0, \infty)$ and $p(x, y)=\frac{x+y}{2}$, then $(X, p)$ is a weak partial metric space and is not a partial metric space.

Theorem 2.1. ([2]) Let $(X, p)$ be a weak partial metric space. Then $d_{w}(x, y)$ : $X \times X \rightarrow \mathbb{R}_{+}$is a metric on $X$.

Remark 2.2. In a weak partial metric space, the convergence of sequences, Cauchy sequences and completeness are defined as in partial metric space.

Theorem 2.2. ([2]) Let $(X, p)$ be a weak partial metric space.

a) $\left\{x_{n}\right\}$ is a Cauchy sequence in $(X, p)$ if and only if $\left\{x_{n}\right\}$ is a Cauchy sequence in metric space $\left(X, d_{w}\right)$.

b) $(X, p)$ is complete if and only if $\left(X, d_{w}\right)$ is complete.

Lemma 2.1. Let $(X, p)$ be a weak partial metric space and $\left\{x_{n}\right\}$ is a sequence in $X$. If $\lim _{n \rightarrow \infty} x_{n}=x$ and $p(x, x)=0$ then

$$
\lim _{n \rightarrow \infty} p\left(x_{n}, y\right)=p(x, y), \forall y \in X \text {. }
$$

Proof. By $\left(w P_{3}\right)$,

$$
p(x, y) \leq p\left(x, x_{n}\right)+p\left(x_{n}, y\right)
$$

hence

$$
p(x, y)-p\left(x, x_{n}\right) \leq p\left(x_{n}, y\right) \leq p\left(x_{n}, x\right)+p(x, y) .
$$

Letting $n$ tend to infinity we obtain

$$
\lim _{n \rightarrow \infty} p\left(x_{n}, y\right)=p(x, y) .
$$


Remark 2.3. Remark 2.1 is still true for weak partial metric spaces.

Definition 2.4. ([6]) Let $(X, d)$ be a metric space and $f, g$ be self mappings on $X$.

1) $\quad f$ is called $g$ - absorbing if there exists $R>0$ such that $d(g x, g f x) \leq R d(f x, g x)$ for all $x \in X$.

Similarly, $g$ is $f$ - absorbing.

2) $f$ is called pointwise $g$ - absorbing if for given $x \in X$ there exists $R>0$ such that $d(g x, g f x) \leq R d(f x, g x)$.

Similarly, $g$ is pointwise $f$ - absorbing.

Remark 2.4. 1) If $(X, p)$ is a weak partial metric space we have a similar definition to Definition 2.4 with $p$ instead $d$.

2) If $g$ is the identity mapping on $X$, then $f$ is trivially absorbing.

\section{Implicit relations}

Definition 3.1. Let $\mathfrak{F}_{W}$ be the set of all lower semi - continuous functions $F$ : $\mathbb{R}_{+}^{5} \rightarrow \mathbb{R}$ satisfying the following conditions:

$\left(F_{1}\right): F$ is nonincreasing in variable $t_{5}$,

$\left(F_{2}\right):$ For all $u, v \geq 0$, there exists $h \in[0,1)$ such that

$\left(F_{2 a}\right): F(u, v, v, u, u+v) \leq 0$ and

$\left(F_{2 b}\right): F(u, v, u, v, u+v) \leq 0$,

implies $u \leq h v$.

$\left(F_{3}\right): F(t, t, 0,0,2 t)>0, \forall t>0$.

Example 3.1. $F\left(t_{1}, \ldots, t_{5}\right)=t_{1}-k \max \left\{t_{2}, t_{3}, t_{4}, \frac{t_{5}}{2}\right\}$, where $k \in[0,1)$.

$\left(F_{1}\right)$ : Obviously.

$\left(F_{2}\right)$ : Let $u, v \geq 0$ be and $F(u, v, v, u, u+v)=\max \left\{u, v, \frac{u+v}{2}\right\} \leq 0$. If $u>v$ then $u(1-k) \leq 0$, a contradiction. Hence $u \leq v$ which implies $u \leq h v$, where $0 \leq h=k<1$.

Similarly, $F(u, v, u, v, u+v) \leq 0$ implies $u \leq h v$.

$\left(F_{3}\right): F(t, t, 0,0,2 t)=t(1-k)>0, \forall t>0$.

The proofs for the following examples are similar to the proof of Example 3.1.

Example 3.2. $F\left(t_{1}, \ldots, t_{5}\right)=t_{1}-k \max \left\{t_{2}, t_{3}, t_{4}, t_{5}\right\}$, where $k \in\left[0, \frac{1}{2}\right)$.

Example 3.3. $F\left(t_{1}, \ldots, t_{5}\right)=t_{1}-k \max \left\{\frac{t_{2}+t_{3}+t_{4}}{3}, \frac{t_{5}}{2}\right\}$, where $k \in[0,1)$.

Example 3.4. $F\left(t_{1}, \ldots, t_{5}\right)=t_{1}^{2}-k \max \left\{t_{2}, \frac{t_{3}+t_{4}}{2}, \frac{t_{5}}{2}\right\}$, where $k \in[0,1)$. 
Example 3.5. $F\left(t_{1}, \ldots, t_{5}\right)=t_{1}^{2}-a \max \left\{t_{2}^{2}, t_{3}^{2}, t_{4}^{2}\right\}-b t_{5}^{2}$, where $a, b \geq 0$ and $a+4 b<1$.

Example 3.6. $F\left(t_{1}, \ldots, t_{5}\right)=t_{1}^{2}-a t_{2} t_{3}-b t_{3} t_{4}-c t_{5}^{2}$, where $a, b, c \geq 0$ and $a+b+4 c<1$.

Example 3.7. $F\left(t_{1}, \ldots, t_{5}\right)=t_{1}^{2}+\frac{t_{1}}{1+t_{5}}-\left(a t_{2}^{2}+b t_{3}^{2}+c t_{4}^{2}\right)$, where $a, b, c \geq 0$ and $a+b+c<$ 1.

Example 3.8. $F\left(t_{1}, \ldots, t_{5}\right)=t_{1}-a t_{2}-b t_{3}-c \max \left\{2 t_{4}, t_{5}\right\}$, where $a, b, c, d \geq 0$ and $a+b+2 c<1$.

Example 3.9. $F\left(t_{1}, \ldots, t_{5}\right)=t_{1}-\frac{a t_{3} t_{4}}{1+t_{2}}-b t_{2}-c\left(t_{3}+t_{4}\right)-d t_{5}$, where $a, b, c, d \geq 0$ and $a+b+2 c+2 d<1$.

Example 3.10. $F\left(t_{1}, \ldots, t_{5}\right)=t_{1}^{2}-t_{1}\left(a t_{2}+b t_{3}+c t_{4}\right)-d t_{5}^{2}$, where $a, b, c, d \geq 0$ and $a+b+c+4 d<1$.

\section{Main results}

Theorem 4.1. Let $(X, p)$ be a weak partial metric space and $A, B, S$ and $T$ be self mappings on $X$ such that

1) $T(X) \subset A(X)$ and $S(X) \subset B(X)$,

2) for all $x, y \in X$

$$
F\left(\begin{array}{l}
p(S x, T y), p(A x, B y), p(S x, A x) \\
p(T y, B y), p(S x, B y)+p(A x, T y)
\end{array}\right) \leq 0 .
$$

If one of $A(X), B(X), S(X), T(X)$ is a closed subset of $X$, then

3) $\mathcal{C}(A, S) \neq \varnothing$,

4) $\mathcal{C}(B, T) \neq \varnothing$.

Moreover, if $S$ is pointwise $A$ - absorbing and $T$ is pointwise $B$ - absorbing, then $A, B, S$ and $T$ have a unique common fixed point $z$ with $p(z, z)=0$.

Proof. Let $x_{0}$ be an arbitrary point of $X$. Since $S(X) \subset B(X)$, there exists $x_{1} \in X$ such that $y_{0}=S x_{0}=B x_{1}$. Since $T(X) \subset A(X)$, there exists $x_{2} \in X$ such that $y_{1}=T x_{1}=A x_{2}$. Continuing this process we construct two sequences $\left\{x_{n}\right\}$ and $\left\{y_{n}\right\}$ in $X$ by

$$
y_{2 n}=S x_{2 n}=B x_{2 n+1}, y_{2 n+1}=T x_{2 n+1}=A x_{2 n+2}, n \in \mathbb{N} .
$$

First we prove that $\left\{y_{n}\right\}$ is a Cauchy sequence in $(X, p)$.

By (4.1) for $x=x_{2 n}$ and $y=x_{2 n+1}$ we have

$$
F\left(\begin{array}{c}
p\left(S x_{2 n}, T x_{2 n+1}\right), p\left(A x_{2 n}, B x_{2 n+1}\right), p\left(S x_{2 n}, A x_{2 n}\right), \\
p\left(T x_{2 n+1}, B x_{2 n+1}\right), p\left(S x_{2 n}, B x_{2 n+1}\right)+p\left(A x_{2 n}, T x_{2 n+1}\right)
\end{array}\right) \leq 0 .
$$


By (4.2) we obtain

$$
F\left(\begin{array}{c}
p\left(y_{2 n}, y_{2 n+1}\right), p\left(y_{2 n-1}, y_{2 n}\right), p\left(y_{2 n-1}, y_{2 n}\right) \\
p\left(y_{2 n}, y_{2 n+1}\right), p\left(y_{2 n}, y_{2 n}\right)+p\left(y_{2 n-1}, y_{2 n+1}\right)
\end{array}\right) \leq 0
$$

By $\left(w P_{3}\right)$ we have

$$
p\left(y_{2 n-1}, y_{2 n+1}\right) \leq p\left(y_{2 n-1}, y_{2 n}\right)+p\left(y_{2 n}, y_{2 n+1}\right)-p\left(y_{2 n}, y_{2 n}\right) \text {. }
$$

By $(4.3)$ and $\left(F_{1}\right)$ we obtain

$$
F\left(\begin{array}{c}
p\left(y_{2 n}, y_{2 n+1}\right), p\left(y_{2 n-1}, y_{2 n}\right), p\left(y_{2 n-1}, y_{2 n}\right), \\
p\left(y_{2 n}, y_{2 n+1}\right), p\left(y_{2 n-1}, y_{2 n}\right)+p\left(y_{2 n}, y_{2 n+1}\right)
\end{array}\right) \leq 0 .
$$

By $\left(F_{2 a}\right)$ we obtain

$$
p\left(y_{2 n+1}, y_{2 n}\right) \leq h p\left(y_{2 n}, y_{2 n-1}\right) .
$$

By (4.1) for $x=x_{2 n}$ and $y=x_{2 n-1}$ we obtain

$$
F\left(\begin{array}{c}
p\left(S x_{2 n}, T x_{2 n-1}\right), p\left(A x_{2 n}, B x_{2 n-1}\right), p\left(S x_{2 n}, A x_{2 n}\right), \\
p\left(T x_{2 n-1}, B x_{2 n-1}\right), p\left(S x_{2 n}, B x_{2 n-1}\right)+p\left(A x_{2 n}, T x_{2 n-1}\right)
\end{array}\right) \leq 0 .
$$

By (4.1) we obtain

$$
F\left(\begin{array}{c}
p\left(y_{2 n}, y_{2 n-1}\right), p\left(y_{2 n-1}, y_{2 n-2}\right), p\left(y_{2 n}, y_{2 n-1}\right), \\
p\left(y_{2 n-1}, y_{2 n-2}\right), p\left(y_{2 n}, y_{2 n-2}\right)+p\left(y_{2 n-1}, y_{2 n-1}\right)
\end{array}\right) \leq 0 .
$$

By $\left(w P_{3}\right)$,

$$
p\left(y_{2 n-2}, y_{2 n}\right) \leq p\left(y_{2 n-2}, y_{2 n-1}\right)+p\left(y_{2 n-1}, y_{2 n}\right)-p\left(y_{2 n-1}, y_{2 n-1}\right) \text {. }
$$

By $(4.4)$ and $\left(F_{1}\right)$ we obtain

$$
F\left(\begin{array}{c}
p\left(y_{2 n}, y_{2 n-1}\right), p\left(y_{2 n-1}, y_{2 n-2}\right), p\left(y_{2 n}, y_{2 n-1}\right) \\
p\left(y_{2 n-1}, y_{2 n-2}\right), p\left(y_{2 n-2}, y_{2 n-1}\right)+p\left(y_{2 n-1}, y_{2 n}\right)
\end{array}\right) \leq 0
$$

By $\left(F_{2 b}\right)$,

$$
p\left(y_{2 n}, y_{2 n-1}\right) \leq h p\left(y_{2 n-1}, y_{2 n-2}\right) \text {. }
$$

Hence,

$$
p\left(y_{n}, y_{n+1}\right) \leq h p\left(y_{n-1}, y_{n-2}\right) \leq \ldots \leq h^{n} p\left(y_{0}, y_{1}\right)
$$

For $n, m \in \mathbb{N}, m>n$, repeating $\left(w P_{3}\right)$ we obtain

$$
\begin{aligned}
p\left(y_{n}, y_{m}\right) & \leq p\left(y_{n}, y_{n+1}\right)+p\left(y_{n+1}, y_{n+2}\right)+\ldots+p\left(y_{m-1}, y_{m}\right) \\
& \leq h^{n}\left(1+h+\ldots+h^{m-1}\right) p\left(y_{0}, y_{1}\right) \\
& \leq \frac{h^{n}}{1-h} p\left(y_{0}, y_{1}\right)
\end{aligned}
$$


Then,

$$
p\left(y_{n}, y_{m}\right) \leq \frac{h^{n}}{1-h} p\left(y_{0}, y_{1}\right) \rightarrow 0 \text { as } n, m \rightarrow \infty
$$

This shows that $\left\{y_{n}\right\}$ is a Cauchy sequence in $(X, p)$. By Theorem $2.2(\mathrm{a}),\left\{y_{n}\right\}$ is a Cauchy sequence in $\left(X, d_{w}\right)$. Since $(X, p)$ is complete, by Theorem $2.2(\mathrm{~b})$, $\left(X, d_{w}\right)$ is a complete metric space. Since $\left\{y_{n}\right\}$ is Cauchy in $\left(X, d_{w}\right)$, it follows that $\left\{y_{n}\right\}$ converges to a point $z$ in $\left(X, d_{w}\right)$. Hence,

$$
\lim _{n \rightarrow \infty} d_{w}\left(y_{n}, z\right)=0
$$

By Remark 2.3, (2.1) and (4.5) we obtain

$$
p(z, z)=\lim _{n \rightarrow \infty} p\left(y_{n}, z\right)=\lim _{n, m \rightarrow \infty} p\left(y_{n}, y_{m}\right)=0
$$

Also, by Theorem 2.2, $S x_{2 n} \rightarrow z, T x_{2 n+1} \rightarrow z, B x_{2 n+1} \rightarrow z, A x_{2 n+2} \rightarrow z$. Suppose that $T(X)$ is a closed subset in $(X, p)$. Then

$$
\lim _{n \rightarrow \infty} T x_{2 n+1}=z \in T(X) .
$$

Since $T(X) \subset A(X)$, there exists $u \in X$ such that $z=A u$.

By (4.1) for $x=u$ and $y=x_{2 n+1}$ we obtain

$$
\begin{gathered}
F\left(\begin{array}{c}
p\left(S u, T x_{2 n+1}\right), p\left(A u, B x_{2 n+1}\right), p(S u, A u), \\
p\left(T x_{2 n+1}, B x_{2 n+1}\right), p\left(S u, B x_{2 n+1}\right)+p\left(A u, T x_{2 n+1}\right)
\end{array}\right) \leq 0, \\
F\left(\begin{array}{c}
p\left(S u, y_{2 n+1}\right), p\left(A u, y_{2 n-1}\right), p(S u, A u), \\
p\left(y_{2 n+1}, y_{2 n}\right), p\left(S u, y_{2 n}\right)+p\left(A u, y_{2 n+1}\right)
\end{array}\right) \leq 0 .
\end{gathered}
$$

Letting $n$ tend to infinity, by Lemma 2.1, and (4.6) we have

$$
F(p(S u, z), 0, p(S u, z), 0, p(S u, z)) \leq 0
$$

which implies by $\left(F_{2 b}\right)$ that $p(S u, z)=0$, i.e. $z=S u$. Hence, $z=A u=S u$ and $\mathcal{C}(A, S) \neq \varnothing$.

Since $z \in S(X) \subset B(X)$, then, there exists $v \in X$ such that $z=B v$. We prove that $B v=T v$.

By (4.1), for $x=u$ and $y=v$ we obtain

$$
\begin{gathered}
F\left(\begin{array}{c}
p(S u, T v), p(A u, B v), p(S u, A u), \\
p(T v, B v), p(S u, B v)+p(A u, T v)
\end{array}\right) \leq 0, \\
F(p(z, T v), 0,0, p(z, T v), 0+p(z, T v)) \leq 0 .
\end{gathered}
$$


By $\left(F_{2 a}\right)$ we have $p(z, T v)=0$, which implies $z=T v=B v$. Hence, $z=A u=$ $S u=B v=T v$ with $p(z, z)=0$.

Moreover, if $S$ is pointwise $A$ - absorbing, there exists $R_{1}>0$ such that

$$
p(A u, A S u) \leq R_{1} p(A u, S u)=R_{1} p(z, z)=0 .
$$

Hence, $z=A u=A S u=A z$ and $z$ is a fixed point of $A$.

By (4.1) we have

$$
\begin{gathered}
F\left(\begin{array}{c}
p(S z, T v), p(A z, B v), p(S z, A z), \\
p(T v, B v), p(S z, B v)+p(A z, T v)
\end{array}\right) \leq 0, \\
F(p(S z, z), 0, p(S z, z), 0, p(S z, z)+p(S z, z)) \leq 0,
\end{gathered}
$$

which implies by $\left(F_{2 b}\right)$ that $p(z, S z)=0$. Hence, $z=S z$ and $z$ is a common fixed point of $A$ and $S$.

If $T$ is pointwise $B$ - absorbing, then there exists $R_{2}>0$ such that

$$
p(B v, B T v) \leq R_{2} p(B v, T v)=R_{2} p(z, z)=0 .
$$

Hence, $z=B v=B T v=B z$ and $z$ is a fixed point of $B$.

By (4.1) we have

$$
\begin{gathered}
F\left(\begin{array}{c}
p(S u, T z), p(A u, B z), p(S u, A u), \\
p(T z, B z), p(S u, B z)+p(A u, T z)
\end{array}\right) \leq 0 \\
F(p(z, T z), 0,0, p(z, T z), 0+p(z, T z)) \leq 0
\end{gathered}
$$

which implies by $\left(F_{2 a}\right)$ that $p(z, T z)=0$. Hence, $z=T z$ and $z$ is a common fixed point of $B$ and $T$.

Therefore, $z$ is a common fixed point of $S, T, A$ and $B$ with $p(z, z)=0$.

Suppose that $A, B, S$ and $T$ have two common fixed points $z_{i}, i=1,2$ with $p\left(z_{i}, z_{i}\right)=0$.

By (4.1) we obtain

$$
\begin{gathered}
F\left(\begin{array}{c}
p\left(S z_{1}, T z_{2}\right), p\left(A z_{1}, B z_{2}\right), p\left(S z_{1}, A z_{1}\right), \\
p\left(T z_{2}, B z_{2}\right), p\left(S z_{1}, B z_{2}\right)+p\left(A z_{1}, T z_{2}\right)
\end{array}\right) \leq 0, \\
F\left(p\left(z_{1}, z_{2}\right), p\left(z_{1}, z_{2}\right), 0,0,2 p\left(z_{1}, z_{2}\right)\right) \leq 0,
\end{gathered}
$$

a contradiction of $\left(F_{3}\right)$ if $p\left(z_{1}, z_{2}\right)>0$. Hence, $p\left(z_{1}, z_{2}\right)=0$ which implies $z_{1}=$ $z_{2}$. 
Example 4.1. Let $X=[0,1]$ be and $p(x, y)=\frac{x+y}{2}$, which implies $d_{w}(x, y)=\frac{1}{2}|x-y|$. Hence, $(X, p)$ is a complete weak partial metric space. Let the mappings $S x=0, A x=$ $\frac{x}{x+2}, B x=x, T x=\frac{x}{3}$. Since $A(X)=\left[0, \frac{1}{3}\right], B(X)=[0,1], S(X)=\{0\}, T(X)=\left[0, \frac{1}{3}\right]$, then $T(X) \subset A(X), S(X) \subset B(X)$ and $A(X), B(X)$ and $T(X)$ are closed subsets of $X$.

$$
\begin{aligned}
p(A x, A S x) & =p\left(\frac{x}{x+2}, 0\right)=\frac{x}{2(x+2)}, \\
p(A x, S x) & =p\left(\frac{x}{x+2}, 0\right)=\frac{x}{2(x+2)} .
\end{aligned}
$$

Hence, $p(A x, A S x) \leq R_{1} p(S x, A x)$ with $R_{1} \geq 1$ and $S$ is pointwise $A$ - absorbing.

Similarly,

$$
p(B x, B T x)=p\left(x, \frac{x}{3}\right)=\frac{\frac{x}{3}+x}{2}=\frac{2 x}{3}, p(B x, T x)=p\left(x, \frac{x}{3}\right)=\frac{2 x}{3} .
$$

Hence, $p(B x, B T x) \leq R_{2} p(B x, T x)$ with $R_{2} \geq 1$ and $T$ is pointwise $B$ - absorbing.

On the other hand,

$$
p(S x, T y)=\frac{S x+T y}{2}=\frac{0+\frac{y}{3}}{2}=\frac{y}{6}, p(T y, B y)=\frac{\frac{y}{3}+y}{2}=\frac{2 y}{3} .
$$

Hence,

$$
p(S x, T y) \leq k p(T y, B y),
$$

where $k \in\left[\frac{1}{4}, 1\right]$. Therefore,

$$
p(S x, T y) \leq k \max \{p(A x, B y), p(S x, A x), p(T y, B y), p(S x, B y)+p(A x, T y)\}
$$

with $k \in\left[\frac{1}{4}, 1\right]$.

By Theorem 4.1 and Example 3.1, $A, B, S$ and $T$ have a unique common fixed point $z=0$ and $p(z, z)=0$.

If $A=B=I d$, by Theorem 4.1 and Remark 2.4 (2), we obtain

Theorem 4.2. Let $(X, p)$ be a weak partial metric space and $S$ and $T$ be self mappings on $X$ such that for all $x, y \in X$

$$
F\left(\begin{array}{c}
p(S x, T y), p(x, y), p(x, S x) \\
p(y, T y), p(x, B y)+p(T y, x)
\end{array}\right) \leq 0 .
$$

for some $F \in \mathcal{F}$.

If $S(X)$ or $T(X)$ is a closed subset of $X$, then $S$ and $T$ have a unique common fixed point.

Acknowledgement. The authors thank the anonymous reviewer for his/her detailed comments and suggestions, that helped to improve the quality of final version of this paper. 


\section{REF E R E N C E S}

1. I. Altun, F. Sola and H. Simsek: Generalized contraction on partial metric spaces. Topology Appl. 157 (18) (2010), 2778-2785.

2. I. Altun and G. Durmaz: Weak partial metric spaces and some fixed point results. Appl. Gen. Topol. 13 (2) (2012), 179-191.

3. R. P. Chi, E. Karapinar and T. D. Thanh: A generalized contraction principle in partial metric spaces. Math. Comput. Modelling 55 (5-6) (2012), 1673-1681.

4. G. Durmaz, O. Acar and I. Altun: Some fixed point results on weak partial metric spaces. Filomat 27 (2) (2013), 317-326.

5. D. Gopal, A. S. Ranadive and U. Mishra: On some open problems of common fixed point theorems of noncompatible mappings. Proc. Math Soc., B.H.U. 20 (2004), $135-141$.

6. D. Gopal, A. S. Ranadive and R. P. Pant: Common fixed points of absorbing maps. Bull. Marathwada Math. Soc. 91 (2008), 43-48.

7. D. Gopal, M. Imdad, M. Husaim and D. K. Patel: Proving common fixed point theorems for Lipschitzian type mappings via absorbing pairs. Bull. Math. Anal. Appl. 3 (4) (2011), 92-100.

8. S. GüLYAZ and E. KARAPINAR: A coupled fixed point result in partially ordered partial metric spaces through implicit function. Hacet. J. Math. Stat. 42 (4) (2013), 347-357.

9. S. GülyAz, E. KARAPINAR and I. S. YÜCE: A coupled coincidence point theorem in partially ordered metric spaces with an implicit relation. Fixed Point Theory Appl. (2013), 2013:38.

10. R. Heckmann: Approximation of metric spaces by partial metric spaces. Appl. Categ. Struct. 7 (1999), 71-88.

11. Z. Kadelburg, H. K. Nashine and S. Radenović: Fixed point results under various contractive conditions in partial metric spaces. Rev. R. Acad. Cienc. Exactas Fís. Nat., Ser. A Mat., RACSAM 107 (2) (2013), 241-256.

12. E. Karapinar, D.K. Patel, M. Imdad and D. Gopal: Some nonunique common fixed point theorems in symmetric spaces through $C L R_{(S, T)}$ - property. Int. J. Math. Math. Sci. 2013 (2013), Article ID 753965.

13. S. G. Matthews: Partial metric topology. In: Papers on General Topology and Applications, Eighth Summer Conference at Queens College (S. Andima et al., eds.), Annals of the New York Academy of Sciences 728 (1996), 183-197.

14. U. Mishra, R. P. Pant, R. Kewat: Common fixed points of absorbing mappings satisfying Lipschitz type contractive conditions. Int. J. Pure Appl. Math. 77 (2) (2012), 245-253.

15. U. Mishra and A. S. RANADIVE: Common fixed point of absorbing mappings satisfying implicit relations, to appear.

16. V. PopA: Fixed point theorems for implicit contractive mappings. Stud. Cercet. Ştiinţ., Ser. Mat., Univ. Bacău 7 (1997), 129-133.

17. V. PopA: Some fixed point theorems for compatible mappings satisfying an implicit relation. Demonstr. Math. 32 (1) (1999), 157-163.

18. V. POPA: Common fixed point theorems for compatible mappings of type $(A)$ satisfying an implicit relation. Stud. Cerc. Ştiinţ., Ser. Mat., Univ. Bacău 9 (1999), 165-173. 
19. V. PopA and A.-M. PATriciu: A general fixed point theorem for a pair of self mappings with common limit range property in partial metric spaces. Bul. Inst. Politeh. Iaşi, Secţ. I, Mat. Mec. Teor. Fiz. 61 (65), 3 (2015), 85-99.

20. V. Popa and A.-M. PATRICIU: A general fixed point theorem for a pair of self mappings in partial metric spaces. Acta Univ. Apulensis, Math. Inform. 43 (2015), 93-103.

21. C. Vetro and F. Vetro: Common fixed points of mappings satisfying implicit relations in partial metric spaces. J. Nonlinear Sci. Appl. 6 (2013), 156-164.

\author{
Valeriu Popa \\ "Vasile Alecsandri" University of Bacău \\ 600115 Bacău, Romania \\ vpopa@ub.ro \\ Alina-Mihaela Patriciu \\ "Dunărea de Jos" University of Galaţi \\ Faculty of Sciences and Environment \\ Department of Mathematics and Computer Sciences \\ 800201 Galaţi, Romania
}

Alina.Patriciu@ugal.ro 